\title{
POLÍTICAS EDUCACIONAIS DE CORREÇÃO DE FLUXO NO RS: EFEITOS DA RACIONALIDADE NEOLIBERAL NA GESTÃO ESCOLAR
}

Alana Claudia Mohr ${ }^{1}$

Maria Inês Naujorks ${ }^{2}$

\begin{abstract}
Resumo
Partindo de estudos pós-estruturalistas, tomamos como materialidade analítica os Programas de Correção de Fluxo adotados na Rede Estadual do Rio Grande do Sul, considerando que estes são tecidos com base em uma racionalidade que vem nomeando, de determinadas formas, sujeitos, ações e condutas de alunos e professores da Educação Básica. Com isso, buscamos entender as condições de possibilidade que fizeram emergir esses Programas como necessidade implícita no imperativo da inclusão que se encontra no slogan Educação para Todos. Objetivamos compreender o funcionamento desses Programas enquanto estratégia de governamento dos sujeitos que habitam a escola e identificar os efeitos dessa estratégia na gestão escolar e na gerência dos “corpos". A análise realizada neste estudo pretende contribuir para a compreensão de como esses dados produzem representações sobre a eficácia desses Programas no que diz respeito à reparação dos índices de alunos em distorção idade/série no Brasil.
\end{abstract}

Palavras-chave: Programas de Correção de Fluxo; Governamento; Gestão Escolar

\section{INTRODUÇÃOO}

\footnotetext{
${ }^{1}$ Educadora Especial. Mestre em Educação. Doutoranda do Programa de Pós- Graduação em Educação e Professora Substituta do Departamento de Educação Especial da Universidade Federal de Santa Maria. Endereço: Rua Ramiro Barcelos, 983 - Bloco A - apto: 304, CEP: 96540-000, Agudo/RS, Brasil. E-mail: alanamohr.ufsm@gmail.com

${ }^{2}$ Professora Titular aposentada do Departamento de Educação Especial da Universidade Federal de Santa Maria. Credenciada no Programa de Pós-Graduação em Educação - Linha de Pesquisa Educação Especial. Endereço: Rua Dario Pederneiras, 140 - apto: 1001, Bairro Petrópolis, 90630090, Porto Alegre/RS, Brasil. E-mail: minau1990@gmail.com
} 
Nas últimas décadas, principalmente após a Declaração Mundial de Educação para Todos (1990), tem sido cada vez mais comum a implementação de políticas e programas de governo que visam a identificar e prevenir "riscos" relacionados a indivíduos que, por estarem fora dos padrões educacionais/escolares, podem representar distorções nas trajetórias educacionais tidas como "normais". A expansão desses programas apresenta-se como um modelo de investimento do Estado, o qual passa a oferecer recursos que seriam capazes de oportunizar condições para que os sujeitos aprendam condutas e, consequentemente, passem a realizar um empreendedorismo de si.

Neste estudo, partimos do entendimento de que ações e programas desse cunho são, na verdade, estratégias de governamento na contemporaneidade que, ao fim e ao cabo, são desenvolvidas para assegurar o controle sobre os sujeitos com base na aprendizagem por sujeição, estabelecendo práticas que operam na condução do comportamento de cada um e de todos.

Ao circularmos em escolas da Educação Básica, tivemos a oportunidade de conhecer turmas diferentes daquelas tradicionalmente organizadas por série/ano. Dentre essas experiências escolares, encontramos as turmas de correção de fluxo dos Programas "Acelera Brasil" e "Se Liga". Para dar início à problematização proposta neste estudo, buscamos informações no site da Secretaria Estadual de Educação do Rio Grande do Sul (Seduc) sobre os Programas de Correção de Fluxo adotados pela Rede Estadual de Ensino. A Rede Estadual conta com três Programas para atender alunos em defasagem idade/série/ano: "Trajetórias Criativas", "Acelera Brasil" e "Se Liga".

Diante disso, optamos por analisar mais atentamente os Programas "Acelera Brasil" e "Se Liga", a fim de compreender sua relação com as Políticas e Legislações da Educação. É importante ressaltar, no entanto, que essa escolha não aconteceu por acaso, mas de forma intencional, uma vez que a organização e implementação dos Programas "Acelera Brasil" e "Se Liga" ocorrem via uma instituição privada, o Instituto Ayrton Senna, em parceria com o Estado. Além disso, é preciso considerar que esses Programas são tecidos em uma racionalidade neoliberal, que vem nomeando, de determinadas formas, os sujeitos, as ações, as condutas e as vidas nos contextos escolares.

Nosso empreendimento analítico durante a pesquisa partiu de estudos e leituras que adotam a perspectiva pós-estruturalista, a qual tem como um de seus principais representantes o filósofo francês Michel Foucault. Entendemos, juntamente com Foucault, a noção de governamentalidade como um conjunto de técnicas e procedimentos a serviço de um tipo de 
MOHR, A. C.; NAUJORKS, M. I.

racionalidade que se constitui no tripé soberania-disciplina-gestão governamental. A governamentalidade, para Foucault, opera no governo político e no governo como condução das coisas, do Estado, da população e, por fim, dos indivíduos (FOUCAULT, 2010).

Com base no aporte teórico oferecido pelos estudos pós-estruturalistas, buscamos, neste trabalho, entender as condições de possibilidade que fizeram emergir os Programas de Correção de Fluxo nominados “Acelera Brasil” e "Se Liga" como uma necessidade do Estado para prover a inclusão, princípio implícito no compromisso global Educação para Todos. Pretendemos compreender, desse modo, como esses Programas vêm funcionando enquanto estratégia de governamento dos sujeitos escolares.

Para proceder à análise desses Programas, começamos entendendo-os como produtores de práticas discursivas que atuam na condução das atividades escolares projetadas para a correção do fluxo escolar. Tais Programas só ganham existência devido às relações de poder e saber que legitimam e autorizam as práticas de correção de fluxo.

Um primeiro passo analítico envolveu a atenção minuciosa para esses Programas, na intenção de identificar as redes discursivas que os constituem e como estas se articulam com os discursos/enunciados da Educação para Todos, operando, assim, estratégias de governamento. Entendemos, a partir de Foucault (2009), que o discurso é uma prática social produzida nas relações de saber-poder. Enquanto linguagem que produz o real e a realidade, o discurso tem, como efeitos discursivos, a objetivação e subjetivação do sujeito.

A noção de discurso como aporte metodológico e analítico para o desenvolvimento deste trabalho denota, precisamente, o fato de recusarmos as explicações unívocas e as fáceis interpretações, bem como a insistência em buscar o sentido último ou oculto das coisas. São os discursos que exercem seu próprio controle por meio de procedimentos que funcionam, sobretudo, a título de princípios de classificação, de ordenação e de distribuição, como se fosse o caso de submeter outra dimensão do discurso: a do acontecimento e do acaso (FOUCAULT, 2009).

Portanto, analisar o discurso seria contemplar exatamente as relações históricas, práticas muito concretas, que estão "vivas" nos discursos. Analisar textos oficiais, nessa perspectiva, significa tentar escapar da fácil interpretação daquilo que estaria "por trás" dos documentos, procurando explorar ao máximo os materiais, na medida em que eles são uma produção histórica e política, que as palavras são também construções e que a linguagem também é constitutiva das práticas sociais (FISCHER, 2001, p. 199).

Olhar para o discurso e para as práticas discursivas significa perguntar: "por que isso é dito aqui, deste modo, nesta situação, e não em outro tempo e lugar, de forma diferente?" 
POLÍTICAS EDUCACIONAIS DE CORREÇÃO DE FLUXO NO RS: EFEITOS DA RACIONALIDADE NEOLIBERAL NA GESTÃO ESCOLAR

(FISCHER, 2001, p. 205). Essa temporalidade não deve ser entendida e capturada apenas em relação a um determinado tempo e lugar. Precisa ser vista "através dos documentos escolhidos, das práticas a que os textos se referem, da formação social em questão, da trajetória dos conceitos envolvidos e ainda do posicionamento do pesquisador” (Ibid., p. 216).

Partindo da compreensão de que não se pode falar de qualquer coisa em qualquer época sem levar em conta o contexto sócio histórico, a análise que desenvolvemos vai em direção ao entendimento de que um determinado objeto, como os discursos sobre os Programas de Correção de Fluxo, só pode existir sendo determinado por certas "condições, na dinâmica de um feixe de relações, e que há condições de aparecimento histórico de um determinado discurso, relativas às formações não discursivas (instituições, processos sociais e econômicos)" (Ibid., p. 221). Comungamos com Fischer (2001) quando afirma que os discursos que operam os Programas de Correção de Fluxo na Escola só podem ser aprendidos e descritos a partir dos próprios textos. É a partir deles que se torna possível entender as regras pelas quais o jogo de relações entre saberes discursivos e poder, em uma determinada época, fazem aparecer aquele objeto e não outro.

Ressaltamos, ainda, que os efeitos de verdade dos discursos aqui analisados engendram forças e disputam espaços de poder, bem como relações de saber-poder que operam estratégias discursivas capazes de produzir determinadas ações e configurações da gestão escolar e de capturar os "comportamentos" dos sujeitos por meio dos discursos.

As informações sobre os Programas "Se Liga" e "Acelera Brasil" foram retiradas, integralmente, do Guia de Tecnologias Educacionais 2011/2012 do Ministério da Educação (MEC). Esse documento está organizado em cinco blocos de tecnologias, apresentando os Programas de Correção de Fluxo "Se Liga" e "Acelera Brasil" no eixo referente ao EnsinoAprendizagem.

O "Se Liga" é um programa de gestão da alfabetização, caracterizado pela conjugação de princípios, metodologias e materiais pedagógicos pensados e planejados para propiciar o desenvolvimento de habilidades de leitura, escrita e cálculo. Lançado em 2001, consiste em oferecer ações de alfabetização para crianças repetentes no Ensino Fundamental a fim de diminuir a evasão escolar. É implementado na rede pública de ensino (municipal e/ou estadual) após o diagnóstico da alfabetização e da avaliação dos alunos que repetem o ano letivo uma ou mais vezes. Os alunos são identificados com base nos resultados da aplicação de teste de alfabetização de titularidade do Instituto Ayrton Senna. 
MOHR, A. C.; NAUJORKS, M. I.

Já o "Acelera Brasil" foi lançado em 1997 e consiste em um Programa de cunho emergencial criado para corrigir o fluxo no Ensino Fundamental. Esse Programa propõe ações para que os alunos alcancem a série/ano correspondente à sua idade para equilibrar a distorção entre idade e série/ano e, com isso, influenciar positivamente os índices de evasão e repetência escolar. O "Acelera Brasil" é um Programa de Correção de Fluxo para alunos matriculados prioritariamente do $2^{\circ}$ ao $4^{\circ}$ ano do Ensino Fundamental, alfabetizados, que tenham, no mínimo, dois anos de distorção idade/série. Objetiva propiciar a esses alunos a oportunidade de desenvolver as habilidades relativas à primeira fase do Ensino Fundamental.

\section{PROGRAMAS DE CORREÇÃO DE FLUXO: CONDIÇÕES DE POSSIBILIDADE}

Os Programas de Correção de Fluxo aqui analisados são estratégias que, por meio do discurso de verdade sobre a série/ano, a idade e a aprendizagem certa para todos os alunos, produzem as políticas educacionais e são produzidos por elas. Discursos dominantes, complementares, persuasivos, legitimadores, contrastantes e discordantes formam o tecido dos textos dessas políticas. A amplitude desse tecido alarga-se, incluindo documentos, declarações, leis, falas, eventos, materiais de treinamento, sites e uma ampla gama de locações políticas que incorporam declarações autoritárias de valores, prescrições, futuros, prioridades e obrigações (DOHERTY, 2008).

Em uma notícia publicada em 6 de março de 2013 no endereço eletrônico do movimento "Todos pela Educação", fica evidente, de forma bastante clara e objetiva, a real situação do Brasil em relação aos índices educacionais. O texto da notícia, transcrito a seguir, baseia-se nos dados apontados no Relatório de Monitoramento das 5 Metas do Todos pela Educação - "De olho nas metas 2011".

O Brasil não cumpriu as metas intermediárias relativas à Meta 4 do Todos Pela Educação, que estabelece que, até 2022, 95\% ou mais dos jovens brasileiros devem ter concluído o Ensino Fundamental até os 16 anos e, no mínimo 90\%, o Ensino Médio até os 19 anos.

A taxa de conclusão do Ensino Fundamental aos 16 anos registrada em 2011 foi de $64,9 \%$, bem abaixo da meta traçada para este ano, que era de $72,9 \%$. Já a taxa do Ensino Médio finalizado aos 19 anos foi de $51,1 \%$, sendo que a meta parcial era de $53,6 \%$.

Os dados fazem parte do relatório De Olho nas Metas 2012, o quinto relatório de monitoramento das 5 Metas do Todos Pela Educação, divulgado hoje. A base de informações utilizada foi a Pesquisa Nacional por Amostra de Domicílios (Pnad) 2011, publicada no ano passado pelo Instituto Brasileiro de Geografia e Estatística (IBGE).

Observando as unidades da Federação, encontra-se apenas um estado acima das metas para as duas etapas de ensino: o Mato Grosso. Por outro lado, quatorze outras unidades não conseguiram atingir as metas parciais nem do Fundamental nem do 
Médio. São eles Alagoas, Amapá, Amazonas, Bahia, Espírito Santo, Mato Grosso do Sul, Minas Gerais, Pará, Paraná, Rio de Janeiro, Rio Grande do Norte, Rio Grande do Sul, São Paulo e Sergipe.

O relatório ainda revela mais um agravante: o Brasil está, progressivamente, se distanciando das metas projetadas pelo movimento ao longo do tempo. Houve uma piora em relação à publicação anterior, relativa a dados de 2009 - naquele ano, o País havia atingido as metas parciais nas duas etapas de ensino [...].

O De Olho nas Metas 2011 também revelou que o fluxo escolar é um dos principais desafios da Educação brasileira na próxima década. O texto aponta que o País pode não atingir as metas de conclusão do Ensino Fundamental e Médio até 2022, caso não encontre uma solução para questões problemáticas relativas ao atraso escolar, como ingresso tardio, a repetência e o abandono [...]. (BRASIL, 2013).

Na perspectiva da gestão de qualidade da Educação Básica, a Educação para Todos discute a crise da educação no Brasil, ao mesmo tempo em que considera que o poder público sozinho seria ineficiente no tratamento desta. Seria necessário, assim, contar com a participação da sociedade civil e de suas organizações.

A relação de corresponsabilidade da gestão da educação entre o poder público e a sociedade civil parece configurar uma das condições de possibilidade para o investimento na qualidade da educação. E é com esse aspecto que iniciamos a discussão, tendo em vista a necessidade de o sistema público firmar parcerias e alianças com outras instâncias para alcançar e alavancar os índices da educação.

Ao analisarmos, primeiramente, as estatísticas coletadas e publicadas nos Censos Escolares de 2008, 2009, 2010, 2011 e 2012, já que foi a partir de 2008 que esses Programas começaram a ser implementados no Rio Grande do Sul ("Acelera Brasil” em 2008, "Se Liga" em 2009 e "Trajetórias Criativas" em 2012), podemos perceber que a taxa de alunos cursando a série inadequada para a sua idade no Ensino Fundamental era de 22,1\%.

Analisando os dados estatísticos do Censo Escolar de 2010 referentes à matrícula na Educação Básica, percebe-se que houve um decréscimo de aproximadamente $2 \%$ no número de matriculados, o que equivale a 1.030 .563 alunos.

Aliadas a esses dados, notícias divulgadas e vinculadas na mídia nacional enfatizam o alto índice de alunos em distorção de idade/série na rede básica de educação. Essas notícias podem ser aqui tomadas como práticas discursivas, já que seus textos são também "práticos", ou seja, "exigem ser lidos, apreendidos, meditados, utilizados, postos à prova" (FOUCAULT, 2010a, p. 200), fazendo emergir, assim, as condições de possibilidade para que os Programas de Correção de Fluxo se instaurem como a melhor opção para reparar e modificar os índices apresentados.

Mais de 680 mil estudantes do ensino fundamental que estão em séries ou anos incompatíveis com a idade receberão atendimento específico durante o ano letivo de 


\begin{abstract}
2010, até superar a defasagem. Para vencer esse obstáculo em escolas de 1.147 municípios, o Ministério da Educação vai investir cerca de $\mathrm{R} \$ 78$ milhões. A correção do fluxo escolar será feita com o uso de tecnologias educacionais desenvolvidas pelos institutos Ayrton Senna e Alfa e Beto e pelo Grupo de Estudos sobre Educação, Metodologia de Pesquisa e Ação (Geempa). Todas elas préqualificadas pelo MEC. Ao investir na correção de fluxo escolar, o Ministério da Educação espera, segundo Raymundo Ferreira, que ao final de 2010 os estudantes sejam integrados à série ou ano correspondente à idade. O segundo resultado esperado é o aumento do Ideb nas escolas atendidas. A aferição será feita com a aplicação da Prova Brasil, em 2011 (INSTITUTO AYRTON SENNA, 2012).
\end{abstract}

Nessa direção, ao analisarmos a evolução do número de matrículas na Educação Básica por Modalidade e Etapa de Ensino de 2007 a 2011, podemos visualizar o aumento das matrículas em cada etapa ao longo desse período, bem como uma diminuição, que indica a retenção de alunos em determinadas etapas da escolarização. Os dados analisados mostramnos uma maior retenção de matrículas nos anos iniciais do Ensino Fundamental, que são justamente o foco dos Programas de Correção de Fluxo adotados pelo MEC, dispostos no Guia de Tecnologias Educacionais (2011-2012), também adotados pela Rede Estadual do Rio Grande do Sul - os Programas "Se Liga" e "Acelera Brasil”".

O decréscimo observado nas matrículas da Educação Básica de aproximadamente 1\%, o que equivale a 577.270 matrículas, decorre, principalmente, da acomodação do sistema educacional, em especial na modalidade regular do Ensino Fundamental, que apresenta histórico de retenção e, consequentemente, altos índices de distorção idade/série (BRASIL, 2011).

Esses dados mostram que, nos anos iniciais, há um declínio no número de matrículas, o que pode ser percebido também nos anos finais. Tal declínio pode ser compreendido como uma retenção escolar, ou seja, a reprovação dos alunos, que acaba ocasionando a distorção idade/série principalmente nessas etapas da escolarização. Esses dados justificam, novamente, os Programas de Correção de Fluxo adotados, tanto em nível nacional quanto estadual. Isso significa que os dados estatísticos, enquanto tecnologia de governamento, produzem e legitimam o surgimento e a instauração de determinadas políticas e ações de cunho reparador e normalizador, as quais visam a conduzir os alunos a determinados espaços que possibilitarão e impulsionarão o avanço no processo de escolarização, tendo como efeito modificar e alavancar os índices educacionais em relação à retenção escolar.

No Resumo Técnico do Censo Escolar de 2012, podemos visualizar as mesmas variáveis coletadas em 2011, com algumas diferenças quanto aos dados apresentados. Nas estatísticas de 2012, podemos observar uma retenção e diminuição considerável do número de matrículas, além dos anos já evidenciados nas estatísticas de 2011, a partir do $3^{\circ}$ ano nos anos iniciais (seguindo no $4^{\circ}$ e $5^{\circ}$ anos) e do $6^{\circ}$ ano nos anos finais (seguindo no $7^{\circ}, 8^{\circ}$ e $9^{\circ}$ anos). 
Ressaltamos, ainda, que as matrículas em cada uma das etapas (anos iniciais e anos finais) precisam ser compatíveis com as idades adequadas. "Essa compatibilidade só ocorrerá com o aumento da eficiência do sistema no que se refere à capacidade de promover a progressão entre séries/etapas" (BRASIL, 2012, p. 20).

Dessa forma, o que nos interessa com esses dados é problematizar e tensionar os esforços empreendidos pelo Governo a partir da exposição e publicação de determinadas estatísticas em relação à operação de práticas e estratégias para a efetivação de uma Educação para Todos. Isso porque os dados estatísticos, ao evidenciarem e identificarem as taxas dos alunos em distorção de idade/série desde 2007, justificam e potencializam a emergência e permanência de Programas de Correção de Fluxo Escolar.

Esses Programas, portanto, utilizam-se da estatística como uma tecnologia de governamento ao buscarem conduzir e reparar o percurso escolar de alunos na educação regular. Como afirmam Sperrhake e Traversini (2012), a estatística "[...] atua como um instrumento de uma racionalidade governamental (racionalidade neoliberal, na atualidade) que produz números, índices e taxas que são utilizados para governar condutas” (p. 71).

Dessa forma, ao percebermos a estatística como tecnologia de governo quanto a condutas, temos a lente para compreender que os dados dos Censos Escolares operam na/para a funcionalidade e legitimação de determinadas práticas e discursos na educação. Constituemse em estratégias que dirigem modos de gestão da escola como instituição e, ao mesmo tempo, modos de conduzir os sujeitos, sejam eles professores ou alunos, objetivando, assim, condição de possibilidade de reverter ou mudar determinadas situações do fluxo escolar por meio dos índices predeterminados a serem alcançados.

Nesse contexto, em que a qualidade na educação e nos processos escolares passa a ser medida por indicadores, podemos, então, considerar que a arte de governar (FOUCAULT, 2008) os homens demanda a produção de um conjunto de formas de saber e que uma dessas formas "acabou se tornando o maior instrumento da nova racionalidade governamental, a estatística” (SENRA, 1996 apud SPERRHAKE; TRAVERSINI, 2012, p. 70).

O Censo Escolar, realizado anualmente pelo Instituto Nacional de Estudos e Pesquisas Educacionais Anísio Teixeira - Inep é o mais relevante e abrangente levantamento estatístico sobre a Educação Básica no País. Os dados do Censo Escolar constituem a mais completa fonte de informações utilizada pelo Ministério da Educação para a formulação de políticas e para o desenho de programas, bem como para a definição de critérios para o repasse - a escolas, a estados e a municípios - dos diversos tipos de recursos propostos (BRASIL, 2009, p. 1). 
MOHR, A. C.; NAUJORKS, M. I.

Com tamanha força e legitimação discursiva, os indicadores estatísticos usados para medição e avaliação e posteriormente fornecidos e publicados, possibilitam construir um sistema de informações sobre o ensino, assim produzindo um diagnóstico e a própria realidade educacional, bem como o monitoramento das políticas públicas e da atuação do sistema educacional. Por meio desses indicadores, são produzidas ações políticas e educacionais: condições de funcionamento das escolas, estatísticas sobre idade/série e aproveitamento escolar, habilidades que os alunos de determinadas séries têm de adquirir e comparações entre escolas, regiões e estados.

Ao retratar uma realidade de forma objetiva e quantitativa, os discursos, apontando, nomeando e classificando posições, produzem o que pretendem descrever. Nessa lógica, a produção dos discursos, bem como sua aceitação e circulação, está vinculada aos regimes de verdade, que, conforme Foucault, podem ser compreendidos como:

[...] os tipos de discurso que ela acolhe e faz funcionar como verdadeiros; os mecanismos e as instâncias que permitem distinguir os enunciados verdadeiros dos falsos, a maneira como se sanciona uns e outros; as técnicas e os procedimentos que são valorizados para a obtenção da verdade; o estatuto daqueles que têm o encargo de dizer o que funciona como verdade (FOUCAULT, 2012, p. 12).

Na contemporaneidade, o saber estatístico parece ser valorizado como um procedimento ou uma técnica de obtenção da verdade: "pelas estatísticas, através das ciências, fazem-se discursos de verdade" (SENRA, 2005, p. 15). Ele é um dos saberes que constituem um aparato de conhecimento que tem como finalidade tornar os indivíduos governáveis (SPERRHAKE; TRAVERSINI, 2012).

Nesse contexto, cabe recorrer a Foucault (2012, p. 54) quando diz que "a verdade está circularmente ligada a sistemas de poder, que a produzem e apoiam, e efeitos de poder que ela induz e que a reproduzem". A verdade não existe, assim, fora do poder ou sem o poder: ela pertence a este mundo e produz efeitos regulamentados de poder. Isso significa que, em cada momento histórico, determinadas práticas discursivas são legitimadas por redes de poder e saber, as quais autorizam que certas coisas e não outras sejam ditas e pensadas, pois:

[...] o que faz com que o poder se mantenha e que seja aceito é simplesmente que ele não pesa só como uma força que diz não, mas que de fato permeia, produz coisas, induz ao prazer, forma saber, produz discurso. Deve-se considerá-lo como uma rede produtiva que atravessa todo o corpo social muito mais do que uma instância negativa que tem por função reprimir (FOUCAULT, 2012, p. 45). 
Os dados estatísticos publicados, tomados como discurso produtivo de uma verdade do sistema educacional, indicam relações de poder. Os dados dos Censos Escolares criam e ilustram determinadas verdades em relação à situação educacional do país. Ao dizerem a realidade acerca da elevada taxa de alunos em situação de distorção idade/série, produzem e dão condição de possibilidade à emergência e permanência dos Programas de Correção de Fluxo nas Escolas. Esses Programas, por sua vez, com uma função legitimada para operarem determinadas ações e práticas de governamento aos sujeitos escolares, no sentido de "mudar ou reverter" a situação, produzem outros dados, outras estatísticas e outras verdades.

Em 2011, 91,6\% dos alunos do Acelera Brasil foram aprovados e 80,3\% dos alunos que cursaram o Se Liga foram alfabetizados. Esses bons resultados e a motivação dos educadores e alunos contribuem para a continuidade dos programas do Instituto Ayrton Senna, que fazem parte da política pública de correção de fluxo adotada pelo Estado (INSTITUTO AYRTON SENNA, 2012).

A partir desses "bons resultados", conforme destacado no excerto acima, há possibilidade de questionarmos a eficiência e necessidade desses Programas, uma vez que toda essa rede discursiva posta em operação para a sua legitimação e consolidação como imperativo para alcançar a Educação para Todos coloca em operação outras relações, dentre elas, a relação público/privado.

\section{A GESTÃO DA EDUCAÇÃO: EFEITOS DA RACIONALIDADE NEOLIBERAL NA GERÊNCIA DA ESCOLA PARA TODOS}

Na lógica neoliberal, a Educação para Todos constitui-se como um princípio de relação entre a escola e todos os sujeitos, recorrendo à perspectiva das parcerias com todos os âmbitos da sociedade. O Estado tem a função de organizar e implementar determinadas ações e políticas que proporcionem o aumento dos índices educacionais e uma Educação para Todos de qualidade. O Estado oferece a implementação dos Programas de Correção de Fluxo, e essa implementação só é possível por meio de parcerias com outras instituições. Feito seu "papel”, o Estado deposita no sujeito-aluno a responsabilidade de desenvolver condições de participação, já que todos devem ter condições de investimento em si para se autogerir, alcançando possibilidades de participação e avanços em seu processo de escolarização.

Tendo em vista o que tem sido produzido e que vem organizando os sistemas educacionais do país, compreendemos que as ações organizadas e operadas pelos Programas de Correção de Fluxo, além de terem o objetivo de alavancar e melhorar os índices 
MOHR, A. C.; NAUJORKS, M. I.

educacionais, agem sobre o sujeito-aluno no sentido de conduzi-lo à norma, ou seja, à normalização. Entendemos também que essa condução dos sujeitos-alunos para esses espaços de "correção" só se tornou possível a partir de uma gestão da educação. Houve um esforço e um investimento muito produtivo na mobilização de todos para o envolvimento e comprometimento com a educação, o que ocorreu porque houve condições de possibilidade para tal.

Considerando que os Programas de Correção de Fluxo são implementados por meio de solicitação da própria Escola, a partir dos dados presentes no Censo Escolar e no Índice de Desenvolvimento da Educação Básica (IDEB), podemos afirmar que essa escolha é feita de forma "autônoma". Ou seja, a gestão escolar tem autonomia e liberdade de solicitar ou não a implementação e realização desses Programas na sua Escola. No entanto, cabe ressaltar que essa escolha das escolas é intensamente subjetivada pelos discursos da autorresponsabilização por seus resultados, uma vez que os Programas oferecidos "prometem" inúmeros ganhos e produtivos resultados em relação à escolarização e "sucesso" dos alunos na escola. Então, como não aderir?

Os programas do Instituto Ayrton Senna são soluções educacionais que ajudam a combater os principais problemas da educação pública do País. E contemplam três grandes áreas: educação formal, educação complementar e educação e tecnologia. Implementados em grande escala com estratégias e metas pré-definidas, os programas recebem acompanhamento e avaliações sistemáticas para alcançar um único objetivo: o sucesso do aluno na escola. Todos os programas oferecem subsídios para que a criança e o jovem possam desenvolver seus potenciais. Por isso, trabalham as competências pessoais, cognitivas, relacionais e produtivas (INSTITUTO AYRTON SENNA, 2013).

A esse respeito, Adrião (2006) coloca a autonomia como o centro da ressignificação dos mecanismos da gestão democrática na lógica gerencial. Essa lógica, por sua vez, é entendida no sentido da responsabilização das unidades escolares pelo sucesso ou fracasso das políticas educacionais. Podemos ver operar a relação "mais governo com menos Governo", ou seja, a presença de um estado mínimo na condução e governamento dos sujeitos.

A participação, na lógica da gestão gerencial, consiste no estabelecimento de parcerias com setores sociais que se disponham a colaborar com a melhoria do ensino público (DRABACH, 2011). As escolas, ao optarem pelos Programas, passam a ter um projeto educativo que organiza diferentes ações em prol do princípio da Educação para Todos, preocupando-se com os alunos em distorção idade/série e, consequentemente, com seus índices educacionais nas avaliações (Censo Escolar e IDEB). Pensando que a escola, na figura 
POLÍTICAS EDUCACIONAIS DE CORREÇÃO DE FLUXO NO RS: EFEITOS DA RACIONALIDADE NEOLIBERAL NA GESTÃO ESCOLAR

do gestor escolar, se torna responsável pelos seus resultados, essa instituição busca, por meio de determinadas ações e estratégias, mudar sua “imagem”, optando por aderir aos Programas de Correção de Fluxo. Essa é uma estratégia colocada em operação pelo Estado para governar com mais eficácia e economia. Trata-se, conforme Popkewitz (apud SILVA, 1998, p. 9), de uma "tendência que tem como quadro político mais amplo precisamente o esforço de extensão da esfera da autonomização da sociedade que caracteriza o neoliberalismo".

Fonseca (2008), ao contextualizar as palavras de Foucault, diz que, na racionalidade política da arte de governar neoliberal, se trata de generalizar a forma política do mercado para todo o corpo social, "de modo que esta - a economia de mercado - funcionará como um princípio de inteligibilidade das relações sociais e dos comportamentos individuais" (p. 160). O IAS, por meio dos Programas de Correção de Fluxo, ao colocar-se, e ser colocado, como um dos grandes responsáveis por combater os maiores problemas da educação pública do País mediante ações e estratégias de grande escala, oferece ao Estado uma ação mínima com uma amplitude máxima.

Na medida em que o Estado oferece e implementa ações como esses Programas e estes oferecem as possibilidades para o aluno desenvolver-se, resta às instituições escolares solicitarem e se organizarem para colocar em funcionamento as ações previstas nos Programas, ou seja, resta às escolas, de forma "autônoma e livre", escolher esses Programas. Nesse sentido, o acionamento e a operacionalização desses Programas de iniciativas privadas na educação pública do país são possibilitados e atendem à racionalidade neoliberal que estamos vivendo. Peters (2011) diz que talvez o melhor exemplo da extensão do mercado a novas áreas da vida social seja o campo da educação. Ele justifica dizendo que, "sob os princípios do neoliberalismo, a educação tem sido discursivamente reestruturada de acordo com a lógica do mercado" (p. 213).

Conforme Hattge (2009, p. 140), “as escolas estão sendo chamadas a se autogerirem". Ou seja, o Estado investe em determinadas políticas e ações com o intuito de tornar a escola uma instituição produtiva para o governo, de forma que ela, ao se autogerir (a partir dos princípios de autonomia e livre participação de todos), possa, ao mesmo tempo em que é governada, também governar, empreendendo investimentos no governo da conduta dos gestores, professores, comunidade externa em si própria e nos alunos para alcançarem determinados objetivos, que, no caso deste trabalho, são os índices educacionais referentes aos alunos em distorção idade/série. 
[...] supostamente, um leque de opções se abra a sua frente. Basta fazer as escolhas certas, e qualquer um pode obter sucesso. [...] Esses sujeitos não serão simplesmente governados, mas autogovernados, porque escolhem acreditando escolherem de forma autônoma. Também não podemos esquecer que essa autonomia das escolas e dos sujeitos é econômica para o Estado, que se desobriga de suas funções, porém, continua exercendo o controle, através de mecanismos de avaliação, prestação de contas e outros dispositivos acionados no interior do sistema educacional (HATTGE, 2009, p. 140).

Observamos, assim, que as escolas, sendo produzidas para agirem e se configurarem de tal forma, com liberdade e autonomia, assumem também a responsabilidade por sua própria gestão e com as metas estatais dos fluxos. Os discursos neoliberais, conforme Hattge (2009, p. 142), "se esforçam por construir e difundir a ideia de que cada um é responsável por sua qualificação [...] podemos dizer que, ao adquirirem autonomia, as escolas também se tornam responsáveis pelos seus resultados".

Ressaltamos, entretanto, que essa autonomia de escolha é feita a partir do investimento do Estado, com base em inúmeras estratégias que produzem esses Programas como a melhor opção. Essas estratégias estão relacionadas às Políticas Públicas de Educação do país, além de inúmeras publicações e propagandas enaltecendo e expondo os bons resultados alcançados por tais Programas, como pode ser visualizado novamente no excerto transcrito a seguir.

Para $70 \%$ dos diretores de escolas, os dois programas contribuíram para modificar a visão dos processos de ensino e aprendizagem, inclusive das turmas regulares. $90 \%$ deles disseram ser a favor da continuidade dos programas nas escolas. Em relação aos professores, $60 \%$ dos que deram aulas pelo Acelera Brasil e $80 \%$ dos professores do Se Liga acreditam que os programas modificaram suas visões dos processos de ensino e aprendizagem (INSTITUTO AYRTON SENNA, 2012, p. 1).

Portanto, a autonomia delegada às instituições escolares e a possibilidade de optarem ou não pela implementação dos Programas de Correção de Fluxo ofertados pela Rede Estadual de Educação levam ao governamento dos sujeitos, bem como a um maior direcionamento de suas ações para que atendam aos índices educacionais esperados para a Escola e região. Esse governamento é operado de forma sutil e produtiva a partir do funcionamento de determinadas estratégias já discutidas neste trabalho.

\section{CONSIDERAÇÕES MOMENTÂNEAS - HISTÓRICAS E SOCIAIS}

As condições de possibilidade para a emergência dos Programas de Correção de Fluxo, enquanto estratégia de governamento para que o aluno na condição de sujeito desviante se torne sujeito-aluno da escola contemporânea, dizem respeito à inclusão desse aluno na escola, 
ou seja, ao seu enquadramento nos índices pretendidos, de modo que participe da lógica do neoliberalismo.

Em geral, práticas e pequenas técnicas, como tabelas, gráficos, índices e formulários, fabricam e fixam o indivíduo e sua diferença à medida que acumulam e ordenam uma massa de significações. O sujeito obediente é produzido e sustentado por esse poder, que é pouco notado e difícil de denunciar: um poder que circula por meio das práticas disciplinares em uma rede de instituições sociais como a escola (PIGNATELLI, 2011).

Campanhas governamentais baseadas em estatísticas, em pesquisas acadêmicas, em ações da mídia e em entre outros mecanismos são postas "em funcionamento para operar o convencimento de todos sobre a necessidade de transformação da escola em um espaço aberto à diversidade" (MENEZES, 2011, p. 51).

Os Programas de Correção de Fluxo, ao funcionarem como estratégia de governamento, operam a partir das ações e orientações estipuladas, ou seja, práticas discursivas que buscam enquadrar os indivíduos dentro do contexto escolar, tornando-os sujeitos-alunos a partir de uma norma. Esses Programas validaram-se como um saber verdadeiro e legítimo, sendo dificilmente contestados. Esse efeito da não-contestação pode ser percebido na organização e divulgação dos índices e resultados (estatísticos) alcançados com sua implementação. Esses dados contribuem, assim, para a produção de representações sobre a eficácia dos Programas para atuarem na reparação dos índices de alunos em distorção idade/série no Brasil. Além disso, operam no norteamento das condutas dos sujeitos, governando-os para o discurso de que uma boa educação significa baixos índices de alunos em distorção idade/série, de modo que estes devem sair desse lugar e migrar para o lugar dos alunos que avançaram em seu processo de escolarização, ou seja, que não repetiram o ano.

Não temos o intuito de ordenar o que é ou não verdadeiro ou correto nesses Programas, tampouco de esgotar as possibilidades de tensionamentos e desdobramentos das ações operadas e dos dados estatísticos publicados. Pretendemos, na verdade, a partir do embasamento em determinados conceitos e de filiações teóricas, tensionar e problematizar algumas questões relacionadas a esses Programas, incluindo o modo como estão organizados e objetivados e as condições de possibilidade que balizam sua emergência para o governamento da condução das condutas. É nosso intento, também, lançar um olhar para os efeitos dessa estratégia de governamento na educação e na gestão escolar. 
MOHR, A. C.; NAUJORKS, M. I.

\title{
POLICIES IN EDUCATIONAL RS FLOW CORRECTION: EFFECTS \\ OF THE SCHOOL MANAGEMENT NEOLIBERAL RATIONALITY
}

\begin{abstract}
Starting from post-structuralist studies, we take as analytical materiality the flow correction programs adopted in the State Network of Rio Grande do Sul, considering that these are woven based on a rationality that comes naming of certain forms, subjects, actions and behaviors of students and Basic Education teachers. With this, we seek to understand the conditions of possibility that have emerged these programs as implicit need in the imperative of inclusion that is the slogan Education for All. We aim to understand the operation of these programs while governamento strategy of the subjects who inhabit the school and identify the effects of this strategy in school management and management of "bodies". The analysis in this study will contribute to the understanding of how these data produce representations about the effectiveness of these programs in regard to compensation for students from indices in age / grade distortion in Brazil.
\end{abstract}

Keywords: Flow Correction Programs; Governamento; School Management

\section{POLÍTICAS EDUCACIONALES DE CORRECCIÓN DE FLUJOS EN RS: EFECTOS DE LA RACIONALIDAD NEOLIBERAL EN LA GESTIÓN ESCOLAR}

\begin{abstract}
Resumen
A partir de los estudios post-estructuralistas, tomamos la materialidad como los programas de análisis de flujo de corrección adoptadas en la Red Estado de Rio Grande do Sul, teniendo en cuenta que éstas se tejen basan en una racionalidad que viene de nombres de formas determinadas, temas, acciones y los comportamientos de los estudiantes y profesores de Educación básica. Con esto, buscamos entender las condiciones de posibilidad que han surgido estos programas como necesidad implícita en el imperativo de inclusión que es el lema Educación para Todos. Nuestro objetivo es entender el funcionamiento de estos programas, mientras que la estrategia governamento de los sujetos que habitan en la escuela e
\end{abstract}


POLÍTICAS EDUCACIONAIS DE CORREÇÃO DE FLUXO NO RS: EFEITOS DA RACIONALIDADE NEOLIBERAL NA GESTÃO ESCOLAR

identificar a los efectos de esta estrategia en la gestión escolar y la gestión de los "cuerpos". El análisis en este estudio contribuirá a la comprensión de cómo estos datos producen representaciones acerca de la efectividad de estos programas en lo que se refiere a la reparación de los estudiantes de los índices de distorsión edad / grado en Brasil.

Palabras clave: Programas de Corrección de Flujo; Gobierno; Gestión Escolar

\section{REFERÊNCIAS}

ADRIÃO, T. Educação e produtividade: a reforma do ensino paulista e a desobrigação do Estado. São Paulo: Xamã, 2006.

BRASIL. Declaração Mundial sobre a Educação para Todos: Plano de Ação para Satisfazer as Necessidades Básicas de Aprendizagem. Jomtien, Tailândia. 1990.

Todos pela Educação. 2006. Disponível em:

<http://www.todospelaeducacao.org.br>. Acesso em: 28 de dez. 2016.

. Instituto Ayrton Senna (IAS). Capacitação prepara professores no Rio Grande do Sul. 2012. Disponível em:

〈http://senna.globo.com/institutoayrtonsenna/home/noticias_interna.asp?cod_Noticia=37〉. Acesso em: 28 de dez. 2016.

Instituto Nacional de Estudos e Pesquisas Educacionais Anísio Teixeira. Censo

Escolar 2008. Disponível em: <http://dados.gov.br/dataset/microdados-do-censo-

escolar/resource/77231efb-f805-44eb-9895-a24113970461>. Acesso em: 28 de dez. 2016.

Instituto Nacional de Estudos e Pesquisas Educacionais Anísio Teixeira Censo

Escolar. Censo Escolar 2009.

Disponível em:

<http://download.inep.gov.br/download/censo/2009/TEXTO_DIVULGACAO_EDUCACEN SO_20093.pdf>. Acesso em: 28 de dez. 2016.

Instituto Nacional de Estudos e Pesquisas Educacionais Anísio Teixeira Censo

Escolar. Censo Escolar 2010. Disponível em:

$<$ http://download.inep.gov.br/educacao_basica/censo_escolar/resumos_tecnicos/divulgacao_c enso2010_revisao_04022011.pdf> Acesso em: 28 de dez. 2016.

Instituto Nacional de Estudos e Pesquisas Educacionais Anísio Teixeira Censo

Escolar. Censo Escolar 2011. Disponível em:

$<$ http://download.inep.gov.br/educacao_basica/censo_escolar/resumos_tecnicos/resumo_tecni co_censo_educacao_basica_2011.pdf>. Acesso em: 28 de dez. 2016. 
MOHR, A. C.; NAUJORKS, M. I.

Instituto Nacional de Estudos e Pesquisas Educacionais Anísio Teixeira Censo

Escolar.Censo Escolar 2012. Disponível em:

$<$ http://download.inep.gov.br/educacao_basica/censo_escolar/resumos_tecnicos/resumo_tecni co_censo_educacao_basica_2012.pdf>. Acesso em: 28 de dez. 2016.

, MEC. Guia de Tecnologias Educacionais 2011/12. Brasília: Ministério da Educação, Secretaria de Educação Básica, 2011. Disponível em:

<http://portaldoprofessor.mec.gov.br/storage/materiais/0000016303.pdf>. Acesso em: 28 de dez. 2016.

DRABACH, Nadia P. Gestão Gerencial: A ressignificação dos princípios da gestão democrática. Anais ANPAE. 2011. Disponível em:

<http://www.anpae.org.br/simposio2011/cdrom2011/PDFs/trabalhosCompletos/comunicacoe sRelatos/0413.pdf>. Acesso em: 28 de dez. 2016.

DOHERTY, Robert A. Uma política educacional criticamente formativa: Foucault, discurso e governamentalidade. In: PETERS, M.; BESLEY, T. Por que Foucault?:novas diretrizes para a pesquisa educacional. Tradução Vinicius F. Duarte. Porto Alegre: Artmed, 2008.

FISCHER, Rosa M. B. Foucault e a Análise do Discurso em Educação. Cadernos de Pesquisa, São Paulo: FCC, n. 114, p. 197-223, nov/ 2001.

FOUCAULT, Michel. Segurança, território, população: curso no Collège de France (19771978). Tradução de Eduardo Brandão. São Paulo: Martins Fontes, 2008.

. A ordem do discurso. São Paulo: Editora Loyola, 2009.

. A Governamentalidade. In: MOTTA, M. B. Ditos \& Escritos IV:estratégia, podersaber. 2. ed. Rio de Janeiro: Forense Universitária, 2010.

. O Uso dos Prazeres e as Técnicas de Si. In: MOTTA, M. B. Ditos \& Escritos V: Ética, sexualidade, política. 2. ed. Rio de Janeiro: Forense Universitária, 2010a.

- Microfísica do Poder. Organização e tradução de Roberto Machado - Rio de

Janeiro: Edições Graal, 2012.

HATTGE, Morgana D. Empresariamento da educação e autonomia escolar: estratégias de governamento na escola inclusiva. In: LOPES, M. C.; HATTGE, M. D. (Orgs.). Inclusão Escolar: conjunto de práticas que governam. Belo Horizonte: Autêntica. 2009.

MENEZES, Eliana da C. P. A maquinaria escolar na produção de subjetividades inclusivas. 2011. 189 f. Tese (Doutorado em Educação) - Universidade do Vale do Rio dos Sinos, São Leopoldo.

PIGNATELLI, F. Que posso fazer? Foucault e a questão da liberdade e da agência docente. In: SILVA, T. T. (Org.). O sujeito da educação: estudos foucaultianos. 8. ed. Petrópolis, RJ: Vozes, 2011.

SENRA, N. de C..O saber e o poder das estatísticas: uma história das relações dos estatísticos com os estados nacionais e com as ciências. Rio de Janeiro: IBGE, 2005. 
POLÍTICAS EDUCACIONAIS DE CORREÇÃO DE FLUXO NO RS: EFEITOS DA RACIONALIDADE NEOLIBERAL NA GESTÃO ESCOLAR

SILVA, Tomaz T. da. As pedagogias psi e o governo do eu. In: SILVA, Tomaz T. da (Org.) Liberdades reguladas: a pedagogia construtivista e outras formas de governo do eu. 2 ed. Petrópolis: Vozes, 1998.

SPERRHAKE, R., TRAVERSINI, C. S. O Uso do Saber Estatístico nos Discursos Acadêmicos da Alfabetização. Revista Reflexão e Ação, Santa Cruz do Sul: Universidade de Santa Cruz do Sul, vol. 20, n. 2, p.67-87, jul./dez. 2012.

http://dx.doi.org/10.17058/rea.v20i2.3054

Data de recebimento: $28 / 06 / 2016$

Data de aceite: 29/09/2016 